\title{
Perceptions of school-based service delivery in speech-language pathology among parents of children with and without language difficulties
}

\author{
Hyun Jung Lee', Eun Kyoung Lee ${ }^{2}$ \\ 'Department of Speech-Language Pathology, Honam University, Gwangju; ${ }^{2}$ Department of Speech-Language Therapy, Dongshin University, Naju, \\ Korea
}

Purpose: The purpose of this study was to compare the perceptions of school-based service delivery in speech-language pathology (SLP) among parents of children with and without language difficulties.

Methods: A questionnaire was developed to examine the parental perceptions of and desires for school-based service delivery in SLP. The survey was administered to 55 parents of children with language difficulties and 97 parents of children without language difficulties among parents of children in kindergarten and elementary school.

Results: First, parents of children with language difficulties perceived that their children's language skills had an impact on their academic performance and their peer relationships, while parents of children without language difficulties perceived that their children's language skills had an impact on their academic performance but not their peer relationships. Second, both groups of parents recognized that school-based SLPS were needed to boost their children's academic performance and social communication skills. They also wanted the service to be delivered within their children's school curriculum on a regular basis. Third, each group of parents expected that school-based SLPs would help their children in different areas.

Conclusions: The results of this study are expected to serve as guidance for the development of school-based service delivery in SLP.

Keywords: School-based SLP, Parent perception, Children in kindergarten and elementary school

\section{INTRODUCTION}

Most children develop their communication skills through the course of kindergarten and elementary school, but some children do not have the same levels of language skills as their peers [1]. As language plays a critical role in learning, children with language issues may face certain challenges in their school lives. Their limited language ability can lead to difficulties in learning as well limit their relationships with others in social situations [2-5].

Research has shown that school teachers experience difficulties in meeting the needs of children with language problems [6-8]. In many cases, additional support is required for children with communication disorders to close the gap with their peers [6], and the most important predictor of requiring high-level supports in the school environment is

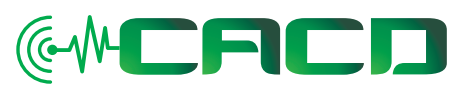

Received: November 24, 2021 Revision: December 15, 2021 Accepted: December 15, 2021

\section{Correspondence:}

Eun Kyoung Lee

Department of Speech-Language Therapy, Dongshin University, 67 Dongshindae-gil, Naju 58245, Korea Tel: +82-61-330-3476

Fax: +82-61-330-3476 E-mail: eklee@dsu.ac.kr

C 2021 The Korean Association of SpeechLanguage Pathologists

This is an Open Access article distributed under the terms of the Creative Commons Attribution NonCommercial License (https://creativecommons.org/ licenses/by-nc/4.0/) which permits unrestricted noncommercial use, distribution, and reproduction in any medium, provided the original work is properly cited. 
the presence of communication difficulties in a student [8].

In response to this demand, speech-language pathologists (SLPs) have been working in school settings for a long time in the United States, Canada, and the United Kingdom. It has recently been reported that more than $50 \%$ of SLP in the United States is served in schools and educational settings [9]. School-based SLP plays a leading role in assessing how a student's communication difficulties actually affect their academic outcomes. School-based SLPs not only directly provide language rehabilitation services, but they also provide expert opinions that allow for language instruction that meets the educational standards of the class to be included in the curriculum of the entire class.

For a successful school-based service delivery in speechlanguage pathology, cooperation with the SLPs and teachers as well as parents is essential. The American Speech-Language-Hearing Association defines family collaboration as an essential component of providing school-based speech rehabilitation services for children of all ages [9]. Kindergarten and elementary school comprise an important period for children, as communication at school during this time not only has an important effect on their adaptation to school life and their learning ability, but it also affects their educational achievement, future life, and society as a whole [10].

During kindergarten and elementary school, children may require short-term or long-term language interventions for various reasons, such as articulation disorders, stuttering, voice misuse, and multicultural environments, as well as language disorders with congenital causes. School-based service delivery in speech-language pathology is desirable in that interventions can be performed naturally and effectively in a practical and familiar environment.

However, as the need for school-based service delivery in speech-language pathology could differ according to each child's language abilities, the parents of children with language problems and the parents of children without language problems may differentially perceive the need for schoolbased service delivery in speech-language pathology. Accordingly, this study investigated the perceptions of school-based service delivery in speech-language pathology among parents of children with and without language problems.

\section{MATERIALS AND METHODS}

\section{Participants}

In this study, questionnaires were distributed to parents of kindergartens and elementary school students residing in Korea. Parents were recruited through language therapy centers, welfare centers, kindergartens, and elementary schools, and 152 responses were obtained. Table 1 presents the participants' demographic information. All participants read the explanation of the purpose and procedure of the study before participating in the study, and they all agreed to participate in the study.

\section{Procedures}

This study was conducted with the approval of the Institutional Review Board of Honam University (1041223-202108HR-16). The purpose of this study was to elucidate the perceptions of parents of children with language problems and parents of children without language problems regarding the difficulties in academic performance and peer relationships caused by language problems, the need for school-based service delivery in speech-language pathology for academic purposes, and the need for school-based service delivery in speech-language pathology for social communication. The questionnaire was composed by referring to previous research by Choi \& Lee [11]. The questionnaire was revised and

Table 1. Participants' demographic information

\begin{tabular}{|c|c|c|c|c|}
\hline & & LD & TD & Total \\
\hline \multirow[t]{3}{*}{ Parents } & Mother & $44(80.0 \%)$ & $90(92.8 \%)$ & $134(88.2 \%)$ \\
\hline & Father & $4(7.3 \%)$ & $6(6.2 \%)$ & $10(6.6 \%)$ \\
\hline & Etc. & $7(12.7 \%)$ & $1(1.0 \%)$ & $8(5.3 \%)$ \\
\hline \multirow[t]{4}{*}{ Children } & Preschoolers (3-5 years) & $55(61.6 \%)$ & $35(38.9 \%)$ & $90(100 \%)$ \\
\hline & Elementary school (Grade 1-3) & $25(69.4 \%)$ & $11(30.6 \%)$ & $36(100 \%)$ \\
\hline & Elementary school (Grade 4-6) & $17(65.4 \%)$ & $9(34.6 \%)$ & $26(100 \%)$ \\
\hline & Total & $97(63.8 \%)$ & $55(36.2 \%)$ & $152(100 \%)$ \\
\hline
\end{tabular}

$\mathrm{LD}$, children with language difficulties; TD, children without language difficulties. 
supplemented by two experts (one professor in a speech-language pathology department and one first-class speech language pathologist) after verifying the validity of the contents and the required time. The questionnaire assesses (a) background information on the children and their caregivers, (2) difficulties in academic performance and peer relationships due to language problems, (3) the perceived need for schoolbased service delivery in speech-language pathology for academic purposes, and (4) the perceived need for school-based service delivery for social communication. The questionnaire was administered to parents who were recruited through the language therapy centers, welfare centers, and schools through a Google questionnaire form.

\section{Data Analysis}

The data collected in this study were analyzed using IBM SPSS Statistics version 25.0 (IBM, Armonk, NY, USA). Frequency and percentage were calculated to understand the distribution of responses to the basic information of subjects, and a chi-square $\left(\chi^{2}\right)$ test was conducted to analyze the differences in responses.

\section{RESULTS}

\section{The perception of parents of children with and without language problems in terms of the effects of their children's language problems on their academic performance and their peer relationships}

To determine whether there is a difference in the perceptions of parents of children with language problems and parents of children without language problems in terms of the academic and social difficulties caused by their children's language problems, parents were surveyed on (1) whether their children's language-based skills (speaking, listening comprehension, reading, writing, etc.) affect their academic performance, (2) whether their children actually have difficulties in academic performance due to their language abilities, (3) if so, in which areas specifically they have difficulties, and (4) whether their children have difficulties in their school lives due to difficulties communicating with their peers.

First, in terms of whether language-based skills affect their children's academic performance, the vast majority of both parents of children with language problems $(80.0 \%)$ and parents of children without language problems $(73.2 \%)$ answered 'to a great extent' (Figure 1); these responses were followed in order by 'somewhat' (16.4\% for children with language problems, $20.6 \%$ for children without language problems) and 'average' (3.6\% for children with language problems, $4.1 \%$ for children without language problems), while small number of parents of children without language problems responded 'very little' (1.0\%) or 'not at all' (1.0\%). There were no significant differences between groups.

In terms of whether or not their children actually have difficulties in academic performance due to their language abilities, $98.2 \%$ of parents of children with language problems and $89.7 \%$ of parents of children without language problems answered 'yes', and there was no significant difference between the groups.

For those answering 'yes', regarding the specific area of their children's academic difficulties, parents of children with lan-

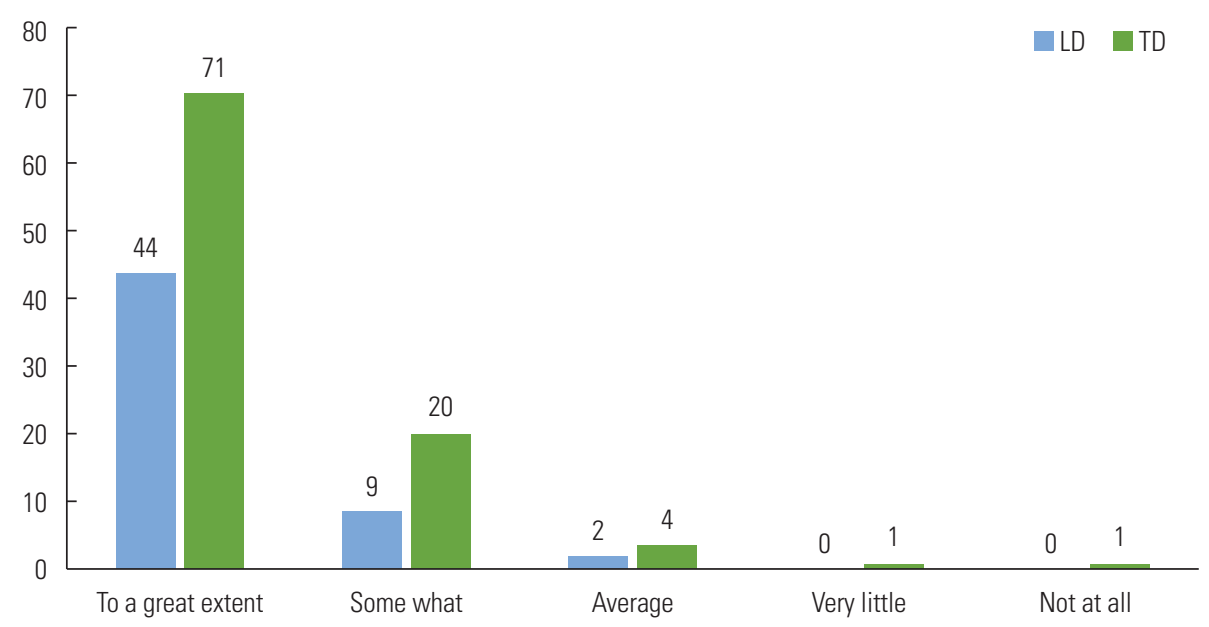

Figure 1. Perceptions of whether language-based skills affect children's academic performance. LD, parents of children with language difficulties; TD, parents of children without language difficulties. 
guage problems responded, in descending order, 'understanding the class contents' (69.2\%), 'attention in class' (53.8\%), 'following instructions' (46.2\%), 'speaking in presentations' and 'reading and writing' (30.8\%). Meanwhile, the responses of parents of children without language problems were, in descending order, 'attention in class' (61.1\%), 'understanding class contents' (55.6\%), 'reading and writing' (27.8\%), 'speaking in presentations' (25.0\%), and 'following instructions' (19.4\%) (Figure 2).

$57.4 \%$ of parents of children with language problems and $11.3 \%$ of parents of children without language problems answered 'yes' to whether children who have difficulties communicating with their peers have difficulties in social school life in addition to academic activities; there is a significant difference between groups $\left(\chi^{2}=.000\right)$ (Figure 3 ).

\section{Parents' awareness of the need for school-based service delivery in speech-language pathology for academic performance}

To determine if there is a difference in the perceptions of parents of children with and without language problems regarding the need for school-based service delivery in speech-language pathology for academic purposes, parents were asked (1) whether or not it is necessary to provide school-based service delivery in speech-language pathology for students who have difficulties in academic performance, (2) what type of support they would desire in such school-based service delivery, and (3) what areas they expected would be helpful when applying school-based service delivery.

First, $100 \%$ of parents of children with language problems and $99.0 \%$ of parents of children without language problems answered 'yes' to the need for school-based service delivery in speech-language pathology for students who have difficulties in academic performance, and there was no significant difference between groups.

Regarding the desired support method when applying for school-based service delivery in speech-language pathology, both parents of children with language problems (50.9\%) and those without language problems (57.0\%) most wanted 'curriculum-based support'; beyond that, parents of children with language problems wanted 'parent counseling support' (25.5\%) and 'extracurricular support' (23.6\%) whereas parents of children without language problems responded with equal levels of 'extracurricular support' and 'parental counseling support' at $21.5 \%$ (Figure 4 ).

Regarding the areas that are expected to be helpful when applying school-based service delivery in speech-language

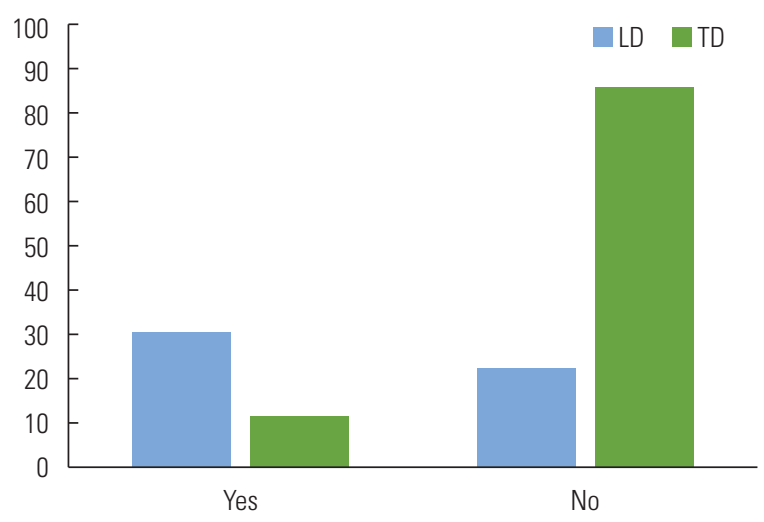

Figure 3. Difficulties in communication with peers. LD, parents of children with language difficulties; TD, parents of children without language difficulties.

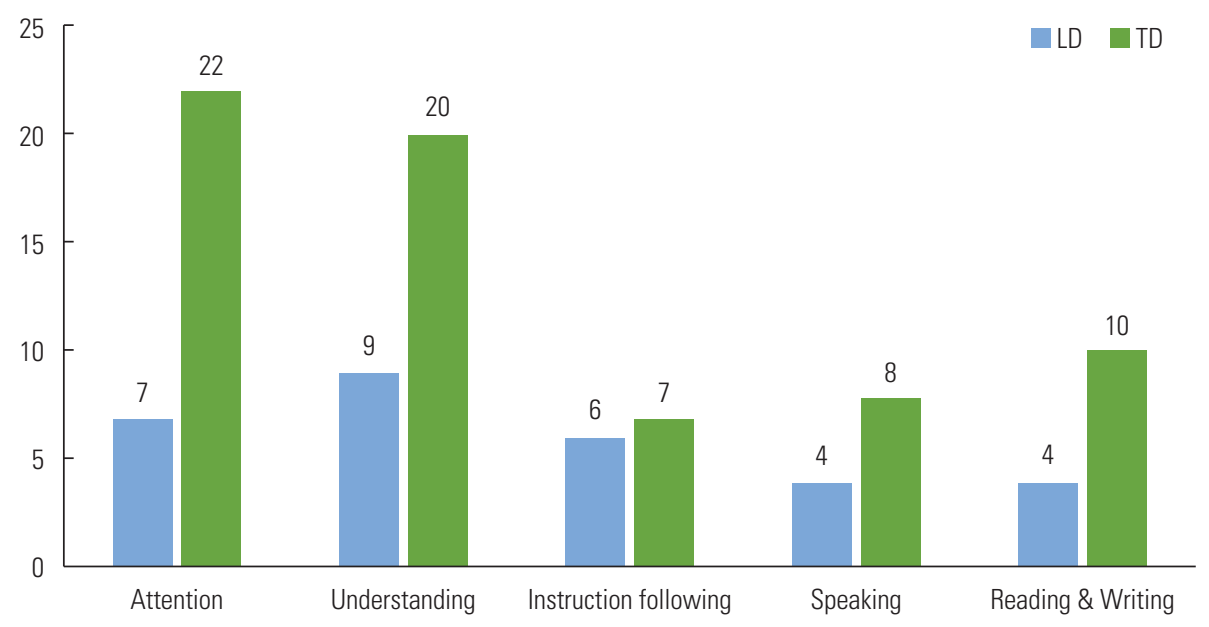

Figure 2. Specific areas of academic difficulties. $L D=$ parents of children with language difficulties. TD=parents of children without language difficulties 
pathology, parents of children with language problems showed the highest responses in 'improvement of academic performance' and 'improvement of social communication skills' at $30.9 \%$, followed in order by 'improvement of school adjustment' (27.3\%) and 'improvement of peer relationships' (9.1\%) (Figure 5). Meanwhile, for parents of children without language problems, 'improvement of school adjustment' was the most common response at $47.3 \%$, followed in descending order by 'improvement of social communication skills' (28.0\%), 'improvement in academic performance' (18.3\%), and 'improvement in peer relationships' (6.5\%).

\section{Awareness of parents of children with and without language problems on the need for school-based service delivery in speech-language pathology for social communication skills}

To determine whether there is a difference in the perceptions of parents of children with and without language problems on the need for school-based service delivery in speech-language pathology for social communication skills, it was examined (1) whether or not it is necessary to provide school-based service delivery in speech-language pathology for students who have difficulties in social communication skills, (2) what type of support parents desired in such school-based service delivery, and (3) what areas they expected to be helpful when applying school-based service delivery.

First, $94.5 \%$ of parents of children with language problems and $94.8 \%$ of parents of children without language problems answered 'yes' to the need for school-based service delivery

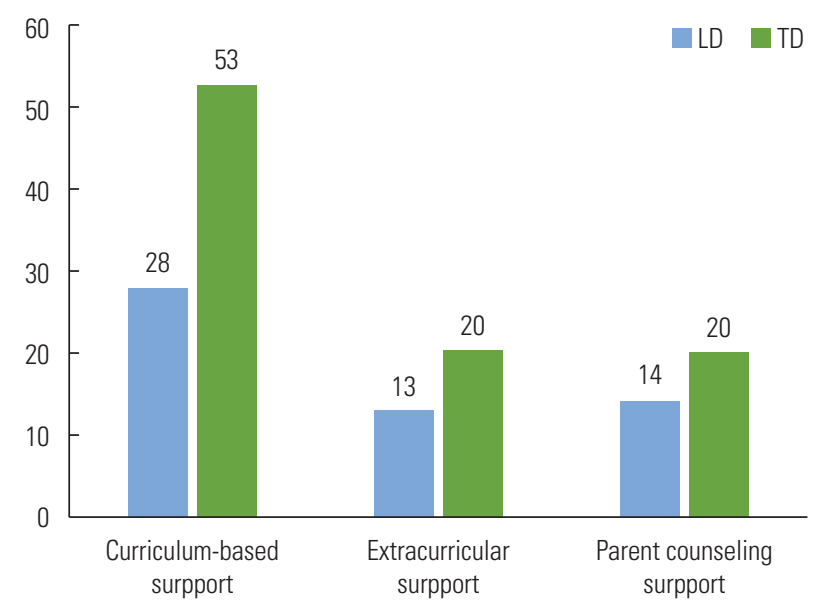

Figure 4. Desired school-based speech-language therapy method for academic performance. LD, parents of children with language difficulties; TD, parents of children without language difficulties. in speech-language pathology for students who have difficulties in social communication, and there was no significant difference between groups.

Regarding the desired support method for school-based service delivery, both parents of children with language problems $(73.6 \%)$ and those without language problems (72.8\%) most wanted 'curriculum-based support'. In the case of parents of children with language problems, 'parent counseling support' (18.9\%) and 'early detection of problem children' (7.5\%) followed as the most common responses, and no such parents wanted 'extracurricular support' (Figure 6). Among parents of children without language problems, 'early detection of problem children' accounted for $16.3 \%$ of responses, followed by 'extracurricular support' and 'parent counseling support' which both accounted for $5.4 \%$.

Regarding the areas that are expected to be helpful when applying for school-based service delivery in speech-language pathology, among parents of children with language problems, 'reducing the cost of private education and speech therapy' was the most common response at $25.5 \%$, followed in descending order by 'improvement of social communication skills' (23.6\%), 'early detection of problem children' (21.8\%), 'improvement of school adjustment' (20.0\%), 'improvement of academic performance' (5.5\%), and 'improvement of peer relationships' (3.6\%) (Figure 7). For parents of children without language problems, 'improvement of school adjustment' was the most common response at $26.6 \%$, followed in descending order by 'early detection of problem children' (22.3\%), 'improvement of social communication

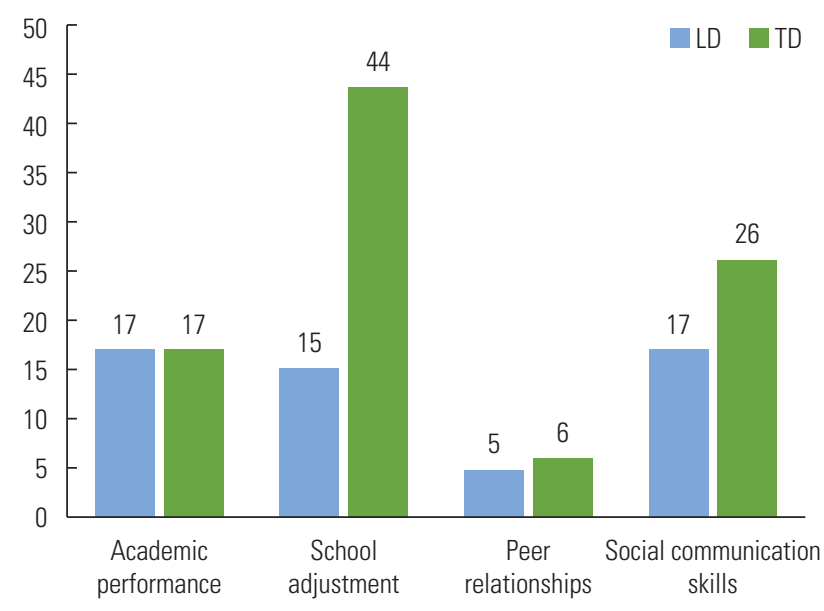

Figure 5. Supported area of school-based speech-language therapy for academic performance. LD, parents of children with language difficulties; TD, parents of children without language difficulties. 


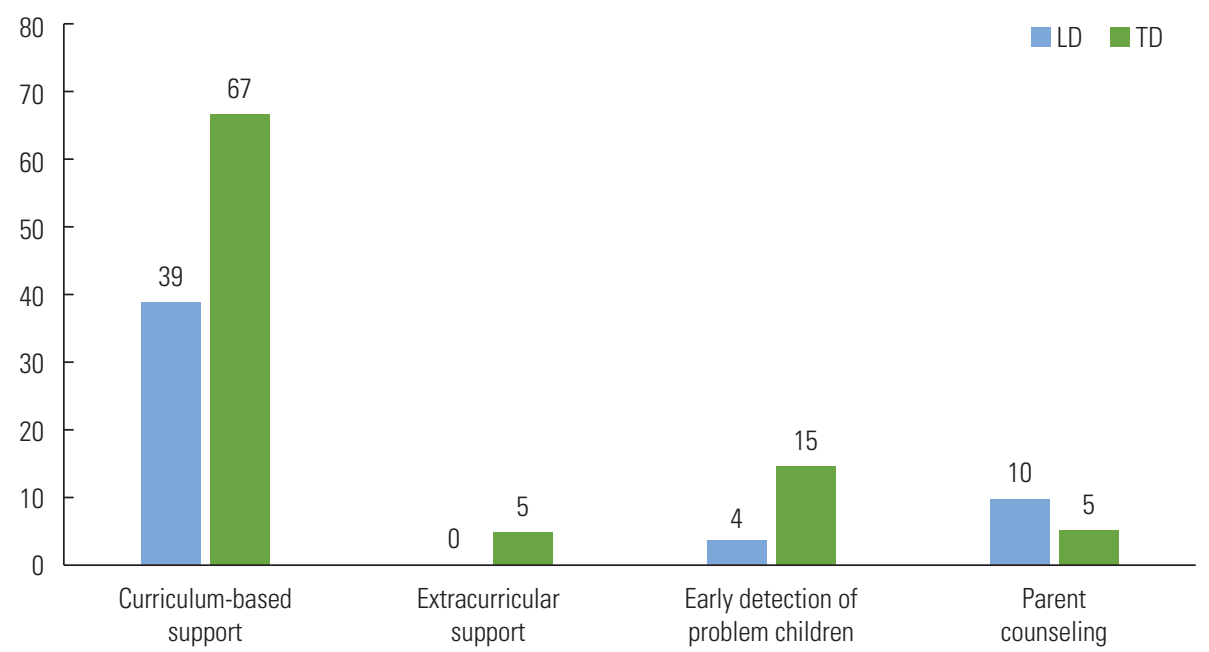

Figure 6. Desired school-based speech-language therapy method for social communication skills. LD, parents of children with language difficulties; TD, parents of children without language difficulties.

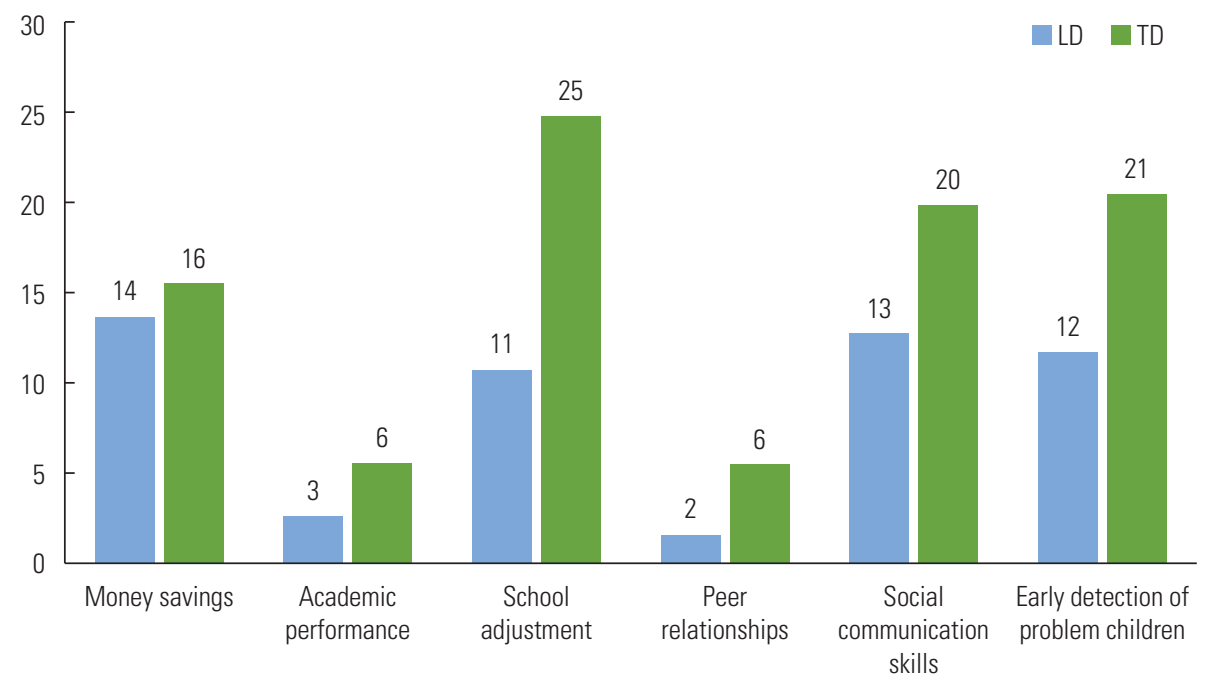

Figure 7. Supported area of school-based speech-language therapy for social communication skills. LD, parents of children with language difficulties; TD, parents of children without language difficulties.

skills' (21.3\%), 'reducing the cost of private education and speech therapy' (17.0\%), 'improvement of academic performance' (6.4\%), and 'improvement of peer relationships' (6.4\%).

\section{DISCUSSIONS}

This study aimed to understand the thinking of parents of children with and without language problems in kindergarten and elementary school. The purpose of this study was to compare and analyze the perceptions of the difficulties faced by children with learning problems in academic performance and peer relationships due to their language abilities, and the needs of school-based service delivery of speech-language pathology to improve children's academic performance and social communication skills by group.

First, both parents of children with and without language problems responded that their children had experienced difficulties in school due to their language problems. Considering that, in the school environment, most curriculum activities are conducted through some form of language, it seems natural that children with language problems would have difficulties in school [6]. The results of this survey showed that the same was true for the children without language problems. However, there was a difference in the perceptions of parents of children with and without language problems in 
terms of whether they felt that their children faced difficulties in school life due to the difficulties they had communicating with their peers. Among parents of children with language problems, more than half answered that their children had experienced difficulties due to difficulties communicating with their peers, whereas only $11 \%$ of parents of children without language problems answered 'yes' to the same question. Although both parents of children with and without language problems agree on the importance of school language abilities, parents of children without language problems are mostly aware of the difficulties in classroom discourse and literacy, whereas parents of children with language problems are, in addition to these concerns, also aware of the difficulties in social communication $[2,5]$.

Second, it was found that most parents of children with and without language problems agreed on the need for schoolbased service delivery in speech-language pathology for children who have difficulties in academic performance. Regarding the desired support method for school-based service delivery, more than half of both groups indicated that they wanted 'curriculum-based support' the most, thus indicating that they wanted everyday support included within the school's regular academic curriculum. Most parents of children with and without language problems also agreed on the need for school-based service delivery in speech-language pathology for social communication skills. Regarding the specific support method, more than $70 \%$ of both groups indicated that they wanted 'curriculum-based support', thus indicating that they wanted language intervention in the school environments, where children spend most of their time, rather than the pull-out method. The school environment not only provides opportunities for children receiving language therapy services to learn age-appropriate social communication skills through interactions with their peers, but it also helps in the natural generalization of the various skills acquired [12]. Notably, no parents of children with language problems indicated that they wanted 'extracurricular support'.

Finally, parents of children with and without language problems showed differences in the areas that they expected would be helpful with school-based service delivery in speech-language pathology for academic performance and social communication skills. Among parents of children without language problems, in both cases, they said that it would be most helpful for 'improving school adjustment', whereas among parents of children with language problems, the service for academic performance would be most helpful for 'improving academic ability' whereas that for social communication skills would be most helpful for 'improving social communication skills' and 'reducing private education and speech therapy costs.' In other words, in the case of parents of children without language problems, it is expected that school-based service delivery in speech-language pathology will be helpful overall, whereas in the case of parents of children with language problems, it is expected that the service for academic performance will be particularly helpful in the academic area and the service for social communication skills will be particularly helpful in the social communication area. This is because children with language problems experience difficulties in their school lives due to their language problems, and they want specific and effective supports. When the service was provided based on the school curriculum in school environment, the language therapy had a positive effect on the academic achievement of the target students.

In conclusion, the results of this study show that parents of children with and without language problems in kindergarten and elementary school regard language abilities as important in their children's school lives, and they therefore strongly demand the need for school-based service delivery in speechlanguage pathology.

Recently, there has been a movement to provide schoolbased service delivery in speech-language pathology in Korea, such as the "Partial Amendment of the Elementary and Secondary Education Act", which requires special schools or metropolitan/provincial educational administrative institutions to have speech-language pathologists on staff. Schoolbased speech-language pathologists are professionals who help children with various communication difficulties in school environments. Effective and systematic methods should be discussed so that school-based service delivery in speech-language pathology can be effectively established.

\section{REFERENCES}

1. McLeod S, McKinnon DH. Prevalence of communication disorders compared with other learning needs in 14500 primary and secondary school students. International Journal of Language \& Communication Disorders. 2007;42:37-59.

2. Botting N, Conti-Ramsden G. 2000: Social and behavioural difficulties in children with language impairment. Child Language Teaching and Therapy. 2000;16:105-120.

3. McCormack J, McLeod S, McAllister L, Harrison LJ. A systematic review of the association between childhood speech impairment and participation across the lifespan. International Journal of 
Speech-Language Pathology. 2009;11:155-170.

4. McCormack J, Harrison LJ, McLeod S, McAllister L. A nationally representative study of the association between communication impairment at 4-5 years and children's life activities at 7-9 years. 2011.

5. McLeod S, Daniel G, Barr J. “When he's around his brothers... he's not so quiet": The private and public worlds of school-aged children with speech sound disorder. Journal of Communication Disorders. 2013;46:70-83.

6. Dockrell JE, Lindsay G. Children with specific speech and language difficulties-The teachers' perspective. Oxford Review of Education. 2001;27:369-394.

7. Marshall J, Ralph S, Palmer S. 'I wasn't trained to work with them': mainstream teachers' attitudes to children with speech and language difficulties. International Journal of Inclusive Education. 2002;6:199-215.
8. McLeod S, McKinnon DH. Support required for primary and secondary students with communication disorders and/or other learning needs. Child Language Teaching and Therapy. 2010;26: 123-143.

9. American Speech-Language-Hearing Association. School-based service delivery in speech-language-pathology. Retrieved from https://www.asha.org/slp/schools/school-based-service-delivery-in-speech-language-pathology/

10. Grunewald R, Rolnick A. A productive investment: Early child development. Early Child. 2007;17.

11. Choi S, Lee EK. Teachers' awareness and needs of the schoolbased speech-language pathologists. Communication Sciences and Disorders. 2021;26:755-772.

12. Elksnin LK, Capilouto GJ. Speech-language pathologists' perceptions of integrated service delivery in school settings. Language, Speech, and Hearing Services in Schools. 1994;25:258-267. 